IZA DP No. 8726

Intrahousehold Decision Making and Fertility

Matthias Doepke

Fabian Kindermann

December 2014

Forschungsinstitut zur Zukunft der Arbeit Institute for the Study of Labor 


\title{
Intrahousehold Decision Making and Fertility
}

\author{
Matthias Doepke \\ Northwestern University \\ and IZA
}

\section{Fabian Kindermann}

University of Bonn

\section{Discussion Paper No. 8726 \\ December 2014}

\author{
IZA \\ P.O. Box 7240 \\ 53072 Bonn \\ Germany \\ Phone: +49-228-3894-0 \\ Fax: +49-228-3894-180 \\ E-mail: iza@iza.org
}

Any opinions expressed here are those of the author(s) and not those of IZA. Research published in this series may include views on policy, but the institute itself takes no institutional policy positions. The IZA research network is committed to the IZA Guiding Principles of Research Integrity.

The Institute for the Study of Labor (IZA) in Bonn is a local and virtual international research center and a place of communication between science, politics and business. IZA is an independent nonprofit organization supported by Deutsche Post Foundation. The center is associated with the University of Bonn and offers a stimulating research environment through its international network, workshops and conferences, data service, project support, research visits and doctoral program. IZA engages in (i) original and internationally competitive research in all fields of labor economics, (ii) development of policy concepts, and (iii) dissemination of research results and concepts to the interested public.

IZA Discussion Papers often represent preliminary work and are circulated to encourage discussion. Citation of such a paper should account for its provisional character. A revised version may be available directly from the author. 
IZA Discussion Paper No. 8726

December 2014

\section{ABSTRACT}

\section{Intrahousehold Decision Making and Fertility}

The economic theory of fertility choice builds predominantly on the unitary model of the household, in which there is a single household utility function and potential intra-household disagreement is abstracted from. Empirical evidence suggests, however, that many (potential) mothers and fathers disagree on whether to have children, on how many children to have, and on when to have them. In this paper, we review existing work that brings models of intrahousehold conflict and bargaining to bear on fertility choice, and we point out promising future directions for this line of research.

JEL Classification: D13, J12, J13

Keywords: fertility, bargaining, child care, limited commitment

Corresponding author:

Matthias Doepke

Department of Economics

Northwestern University

2001 Sheridan Road

Evanston, IL 60208

USA

E-mail: doepke@northwestern.edu

\footnotetext{
* We thank Veronika Selezneva for helpful comments and suggestions. Financial support from the National Science Foundation (grant SES-1260961) is gratefully acknowledged.
} 


\section{Introduction}

Having a baby is perhaps the best example of a joint decision of two people: Without both a mother and father contributing, it is not possible to have one. This observation suggests that agreement between the parents is an important pre-condition for having a baby, and that disagreement is a potential reason for a lack of babies. Empirical evidence suggests that disagreement about fertility choices is commonplace. Westoff (2010) reports that in 17 out of 18 surveyed African countries men desire more children than women do, with an average gap in desired family size of 1.5 and a maximum of 5.6 in Chad. ${ }^{1}$ In addition to a level difference in the desired fertility of women and men, there is also evidence of considerable heterogeneity across households. In Doepke and Kindermann (2014), we examine fertility preferences using data from a new survey, the Generation and Gender Program, which is carried out in panel form in several (mostly European) countries. The survey includes questions about each partner's desire for the arrival of another child. We find that conditional on having already one child and at least one partner desiring another child, there is disagreement about having a baby among more than 30 percent of couples. For couples having two children already, the rate of disagreement about having another one (conditional on at least one spouse wanting the baby) is above 50 percent.

The data on fertility preferences suggests at least the possibility that within-household disagreement on fertility is an important determinant of fertility outcomes. The economic literature on fertility choice, however, has mostly abstracted from the possibility of disagreement. Starting with the seminal contribution of Becker (1960), the vast majority of economic models of fertility have been based on a unitary model of the household, where the household is conceived as a single entity with a single utility function. While the unitary model has led to many important insights, there is now a substantial literature in family economics arguing that the unitary model is empirically rejected when compared to alternatives that allow for disagreement between different members of a family. Non-unitary models have been successfully applied to issues such as the allocation of consumption within the family, the determination of household labor supply, and the impact of the possibility of divorce on family decisions.

In this paper, we examine how models of fertility choice that allow for disagreement between the partners can contribute to explaining fertility in the data. When thinking about fertility decisions from this point of view, a few questions immediately emerge: What de-

1 Surveys were carried out in 1999 to 2008; see Westoff (2010), Table 6.2. 
termines whether partners have different preferences about children? If they disagree on having a baby, how is this disagreement resolved? Do they usually come to a mutually agreeable conclusion, and if so, how? What does this bargaining process imply for how the burden of raising children is shared within the family? And how does the extent of disagreement between spouses determine how many children are born overall?

Definitive answers for these questions are still lacking, and we believe that answering them should be an important part of the research agenda in the economics of fertility in the years to come. In this chapter, we summarize the progress that has been achieved so far, and point to some directions for future research that we believe to be particular promising. We start by reviewing a set of standard models of intra-household decision making. In Section 3, we summarize the existing literature on non-unitary models of fertility choice. In Section 4, we outline our own ongoing research on this topic and develop directions for future research in this area.

\section{Models of intrahousehold resource allocation}

The analysis of intra household resource allocation goes back to the groundbreaking work of Becker $(1973,1974)$ on the theory of marriage. Becker develops his theory in two steps: He first characterizes the potential gains from marriage over living as two single households, and then outlines mechanism that explain how resources are distributed among partners. $^{2}$

\subsection{The gains from marriage}

In Becker's analysis, a married couple forms a production unit that combines market goods and the time of the two partners to produce output $c$. In simplified terms, we can formalize his theory as follows: Let there be a female and a male partner (indexed by $i=f, m)$ who form a married couple. Both partners are endowed with one unit of time, which they can split between market work $l_{i}$ to generate labor income $w_{i} l_{i}$ and time spent on home production $t_{i}$. The total output of the couple is determined by the production

2 We will use the term marriage throughout this chapter as label for a formal living arrangement between two partners of opposite gender. Most of the theory outlined here would however also apply to other arrangements such as cohabitation. 
function:

$$
c=f\left(x, t_{f}, t_{m}\right)
$$

where $x$ is the total amount of goods purchased in the market. Given the wage rates $w_{i}$, the couple chooses their effort levels $t_{f}$ and $t_{m}$ to maximize total output subject to the budget constraint

$$
x+w_{f} t_{f}+w_{m} t_{m}=w_{f}+w_{m}
$$

and the conditions $x \geq 0$ and $0 \leq t_{f}, t_{m} \leq 1$.

The alternative over living as a couple is to live as two single households. In this case, the single households' production levels would be

$$
\begin{array}{ll}
c_{f}^{0}=\max _{x_{f}^{0}, t_{f}^{0}} f\left(x_{f}^{0}, t_{f}^{0}, 0\right) & \text { s.t. } \quad x_{f}^{0}+w_{f} t_{f}^{0}=w_{f} \quad \text { and } \\
c_{m}^{0}=\max _{x_{m}^{0}, t_{m}^{0}} f\left(x_{m}^{0}, 0, t_{m}^{0}\right) & \text { s.t. } \quad x_{m}^{0}+w_{m} t_{m}^{0}=w_{m} .
\end{array}
$$

$c_{f}^{0}$ and $c_{m}^{0}$ can be viewed as the outside options of the two partners. Living as a married couple provides additional benefits only if total production of the married couple is greater than the sum of individual single household productions, i.e.

$$
c>c_{m}^{0}+c_{f}^{0}
$$

Looking at this simple specification of a married couple's decision problem, one can identify three sources of the gains of the marriage:

1. Specialization: If the wages of the spouses differ, then the total output of the couple may increase if the partner with the higher wage specializes in market work and the other one in household production.

2. Complementarity in home production: There may be complementarities in home production such that a larger output is produced when two partners contribute to the production process. ${ }^{3}$

3 The most important good produced in the family with complementarities in production between two partners of opposite gender certainly is children. 
3. Economies of scale in consumption: Economies of scale emerge when the spouses in total need less resources than two individuals to realize the same amount of effective consumption per person (e.g. a couple may need only one house, one fridge, and one TV).

In addition to these consumption-related gains from marriage, there can also be nonpecuniary benefits, i.e. love or match quality.

\subsection{The allocation of resources through the marriage market}

When the gains from marriage are positive, in principle both spouses could be better off married compared to being single. However, the spouses welfare depends not just on the gains from marriage, but also on the distribution of consumption among the spouses. This leads us to the central issue of this chapter, namely how the potential conflict between the spouses regarding the intra-household allocation is resolved. Becker's central assumption for addressing this issue is that the spouses can make binding commitments about the marital allocation before getting married. If there is no choice of potential marriage partners but there are only two people whose only choices are two marry each other or to stay single, the only requirement for the binding pre-marital agreement is that the allocation $c_{f}$ and $c_{m}$ satisfies the conditions:

$$
c_{f}+c_{m}=c \quad \text { as well as } \quad c_{f} \geq c_{f}^{0} \quad \text { and } \quad c_{m} \geq c_{m}^{0} .
$$

The first condition, the resource constraint, tells us that the amount of resources consumed by the two partners can't exceed the total amount of resources available. The two inequality constraints, the participation constraints, ensure that both partners will prefer to live as a couple over living as single.

When there are only two potential spouses and the gains from marriage are positive, there are many allocations that satisfy (6). However, if there are many potential spouses, Becker (1973) argues that the allocation will be pinned down by competition in the marriage market. Consider a setting where there are $n$ females and $n$ males, that each can decide whom to marry. Becker argues that the equilibrium of the marriage market must be characterized by a sorting of the partners as well as respective consumption levels such that no man and woman have the incentive to split up with their current spouse, marry each other, and thereby both obtain a higher consumption level. As a direct result he finds that total output (i.e. the sum of outputs of the couples) will be maximized by such an allocation. 
While the consumption allocation generated by the marriage market is not guaranteed to be unique, uniqueness usually follows if there is a smooth distribution of characteristics of potential spouses.

\subsection{The allocation of resources through ex-post bargaining}

The assumption of full commitment to the marital allocation before the marriage takes place is a strong one, and much of the subsequent literature considers settings where the intra-household allocation is determined ex-post when the spouses are already married. Becker (1974) develops the notion of caring. He assumes that one partner, the altruist, has all the power to determine the distribution of resources, but derives utility from the other spouse's consumption. This leads to a unique distribution of resources between the partners. In the most extreme case in which own consumption and consumption of the partner weigh equally in the utility function of the altruist, resources will be split equally. ${ }^{4}$

In more general settings where none of the spouses has the entire decision power, it is necessary to consider explicit bargaining between the spouses. An early contribution to the bargaining literature is Manser and Brown (1980). They assume that each spouse only derives utility from her own consumption, but the spouses cooperate so that the allocation derived from the bargaining game is Pareto efficient. ${ }^{5}$ Manser and Brown study potential bargaining rules according to which the resource allocation in a marriage could be determined: ${ }^{6}$

1. Dictatorial rule: Under the dictatorial rule, only one of the household members, e.g. the wife, has all the power to determine the resource allocation. Consequently, in order to ensure participation of the husband, she will offer him his outside option $c_{m}^{0}$ and consume the entire marital surplus herself, i.e.

$$
c_{f}=c-c_{m}^{0} \text { and } \quad c_{m}=c_{m}^{0} .
$$

4 Becker (1974) discusses the notion of caring within the context of a marriage market with commitment, but the same concept can be applied to a setting with ex-post determination of the allocation of consumption.

5 There is also a literature on non-cooperative bargaining in the household where the spouses may fail to achieve efficiency. See Lundberg and Pollak (1994) for an overview and Doepke and Tertilt (2014) for a recent application of this model in the context of economic development.

6 We assume without loss of generality that utility is linear in consumption levels $c_{i}$. 
2. Symmetric bargaining: One example of symmetric bargaining is Nash bargaining, which leads to an allocation that is the solution to the following optimization problem: ${ }^{7}$

$$
\max _{c_{f}, c_{m}}\left\{\left[c_{f}-c_{f}^{0}\right] \cdot\left[c_{m}-c_{m}^{0}\right]\right\} \quad \text { s.t. } \quad c_{f}+c_{m}=c
$$

With the marital surplus being $c^{\text {sur }}=c-c_{f}^{0}-c_{m}^{0}$, the solution to this bargaining game is

$$
c_{f}=c_{f}^{0}+0.5 \cdot c^{\mathrm{sur}} \quad \text { and } \quad c_{m}=c_{m}^{0}+0.5 \cdot c^{\mathrm{sur}}
$$

Hence, under symmetric Nash bargaining, the marital surplus is split evenly between the two partners. ${ }^{8}$

Figure 1 visualizes the two solutions. Note that both the dictatorial solution and the Nash solution lie on the utility possibility frontier and respect the participation constraints for both partners, i.e. all conditions in (6) are satisfied. In fact all allocations that lie on the bold part of the utility possibility frontier satisfy these conditions. One can represent the set of allocations that satisfy (6) as solutions to the household optimization problem

$$
\max _{c_{f}, c_{m}}\left\{\left[c_{f}-c_{f}^{0}\right]^{\alpha} \cdot\left[c_{m}-c_{m}^{0}\right]^{1-\alpha}\right\} \quad \text { s.t. } \quad c_{f}+c_{m}=c
$$

for $\alpha \in[0,1]$ For a given $\alpha$, the solution is given by:

$$
c_{f}=c_{f}^{0}+\alpha \cdot c^{\mathrm{sur}} \quad \text { and } \quad c_{m}=c_{m}^{0}+(1-\alpha) \cdot c^{\mathrm{sur}}
$$

We can consequently think of $\alpha$ as the bargaining power of the wife. If $\alpha=1$ then the wife has all the power and will act like a dictator, and vice versa for the husband at $\alpha=0$. For $\alpha=0.5$ we are back at the classical Nash bargaining solution advocated by Manser and Brown (1980).

7 Manser and Brown (1980) also study the Kalai-Smorodinsky model, which under the assumption of linear utility is equivalent to the Nash model.

8 The implications of Nash bargaining on household demand functions is studied in more detail in McElroy and Horney (1981). 
Figure 1: Different bargaining solutions

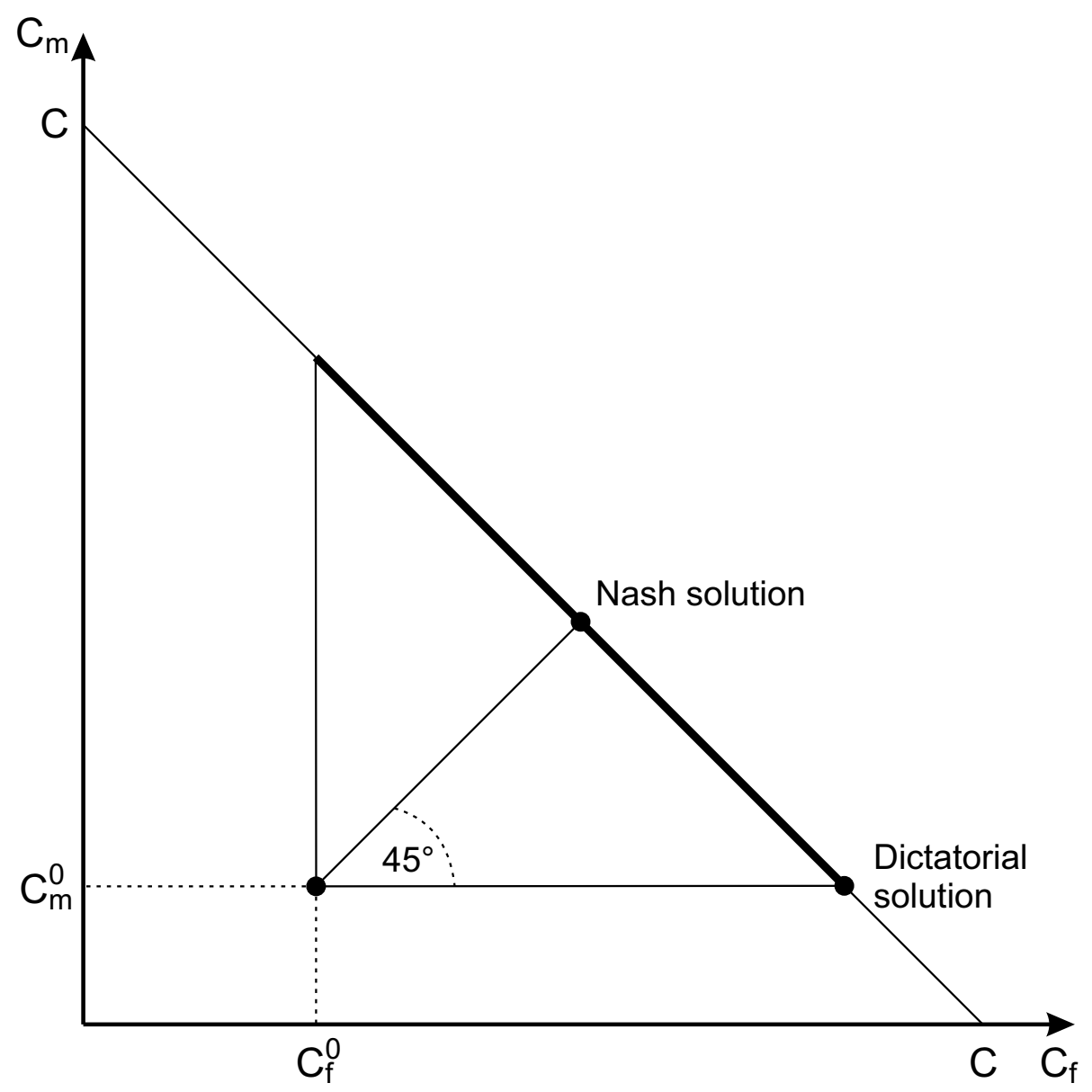

\subsection{More general cooperative bargaining models}

Chiappori $(1988,1992)$ points out that one issue involved in testing cooperative bargaining models such as Manser and Brown (1980) versus alternatives (such as unitary models or non-cooperative bargaining models) is that explicit bargaining models usually imply a particular rule for sharing consumption among the spouses. When the data rejects a model of this kind, it is difficult to know whether this is because cooperative bargaining is rejected in general or because the sharing rule has been misspecified. To overcome this problem, Chiappori $(1988,1992)$ proposes a more general specification of a household resource allocation problem that he calls the collective model. Specifically his approach only rests on two assumptions:

1. The resource allocations in the household are Pareto optimal. 
2. The two partners have egoistic preferences, i.e. they value only their own consumption and leisure.

With only these two assumptions, Chiappori derives falsifiable conditions on household labor supplies that only depend on the aggregate consumption level of the household. This proves valuable to empirical research, since reliable data on individual consumption levels of household members tend to be scarce, while data on individual labor supply and aggregate household consumption are available. In addition, it is possible to derive similar results if some altruism is allowed for.

The main intuition of Chiappori's work is well described in Chiappori (1992). Under the above conditions the household optimization problem can be viewed as a two-stage process. In the first stage, non-labor income of the household $I$ is distributed between the spouses according to some income splitting rule that may depend both on the wage structure and on other factors $y$. As a result, the spouses receive non-labor income shares of

$$
I_{f}=\varphi\left(w_{f}, w_{m}, y\right) \cdot I \quad \text { and } \quad I_{m}=\left(1-\varphi\left(w_{f}, w_{m}, y\right)\right) \cdot I
$$

Given a proper income sharing rule, the solution to the household resource allocation problem is equivalent to the solution of the two single optimization problems

$$
\max _{c_{i}, l_{i}} U_{i}\left(c_{i}, 1-l_{i}\right) \quad \text { s.t. } \quad c_{i}=I_{i}+w_{i} l_{i}, \quad i=f, m .
$$

One implication of this result is that any change in one spouse's wage will affect the other spouse's labor supply solely through an income effect. Hence, any change in non-labor income and/or the wife's wage that has the same effect on the husband's labor supply must lead to the same $c_{m}$. This property makes it possible to recover the sharing rule $\varphi$ from the data and derive labor supply functions.

Using this approach, Browning et al. (1994) show that the allocation of consumption among spouses depends on the their relative incomes and ages using Canadian family expenditure data. Browning and Chiappori (1998) more formally test the symmetry and rank conditions on the Slutsky matrix implied by the collective household decision model. They find that in the data for couples, none of the conditions derived from the collective model are rejected, whereas the symmetry conditions implied by the unitary household model with income pooling are violated. 


\subsection{The role of the outside option}

Within the cooperative bargaining literature relying on explicit bargaining models, most papers assume that the outside options of the spouses reflect the case of divorce. This is a limiting assumption, because it implies that only factors that affect utility in case of divorce can affect bargaining power. To deal with this issue, Lundberg and Pollak (1993) argue that while divorce might be an ultimate threat between married partners, it need not be the most important threat point when the resource distribution within the family is decided on. Instead, they propose the separate spheres bargaining model, which considers a non-cooperative equilibrium during the marriage as the outside option.

In condensed form their model setup looks as follows. Consider two spouses of gender $i=f, m$ who each own some exogenous income $I_{i}$. The spouses have preferences over private consumption $c_{i}$ as well as two public goods $q_{f}$ and $q_{m}$, where the wife has the larger preference for $q_{f}$ and the husband the larger preference for $q_{m}$. The collective goods $q_{f}$ and $q_{m}$ can be viewed as goods typically produced by women and men within the family, respectively. Preferences are represented by utility functions

$$
U_{f}\left(c_{f}, q_{f}, q_{m}\right) \text { and } U_{m}\left(c_{m}, q_{f}, q_{m}\right)
$$

Under Nash bargaining, the couple will solve the optimization problem

$$
\max _{c_{f}, c_{m}, q_{f}, q_{m}}\left[U_{f}\left(c_{f}, q_{f}, q_{m}\right)-U_{f}^{0}\right] \cdot\left[U_{m}\left(c_{m}, q_{f}, q_{m}\right)-U_{m}^{0}\right]
$$

subject to the aggregate resource constraint

$$
c_{f}+c_{m}+q_{f}+q_{m}=I_{f}+I_{m} .
$$

The question that Lundberg and Pollak (1993) are concerned with is how to determine the outside options $U_{f}^{0}$ and $U_{m}^{0}$. The divorce threat bargaining model would imply that the outside options are the utilities the two partner can attain when they decide privately about how much to consume of $c_{i}, q_{f}$ and $q_{m}$, respecting their private budget constraint

$$
c_{i}+q_{f}+q_{m}=I_{i} \quad \text { for } \quad i=f, m .
$$

Consequently, the collective goods in the family $q_{f}$ and $q_{m}$ become private goods for the individuals and the outside options will solely be functions of the individual's income, 
i.e. $U_{f}^{0}=U_{f}^{0}\left(I_{f}\right)$ and $U_{m}^{0}=U_{m}^{0}\left(I_{m}\right)$.

In contrast, the separate spheres bargaining model assumes that when the two partners are unable to cooperate, they revert to a non-cooperative game. Since the wife has the higher preference for $q_{f}$ and the husband the higher preference for $q_{m}$, the non-cooperative equilibrium allocation will be such that $f$ will only contribute to $c_{f}$ and $q_{f}$, while $m$ will split his income between $c_{m}$ and $q_{m}$. This is why the model is called separate spheres. When the non-cooperative game is of Cournot-Nash type, then the demand functions for $c_{f}, c_{m}, q_{f}$ and $q_{m}$ are determined by the following optimization problems

$$
\begin{array}{ll}
\max _{c_{f}^{0}, q_{f}^{0}} U\left(c_{f}^{0}, q_{f}^{0}, \bar{q}_{m}^{0}\right) & \text { s.t. } \quad c_{f}^{0}+q_{f}^{0}=I_{f} \quad \text { and } \\
\max _{c_{m}^{0}, q_{m}^{0}} U\left(c_{m}^{0}, \bar{q}_{f}^{0}, q_{m}^{0}\right) & \text { s.t. } \quad c_{m}^{0}+q_{m}^{0}=I_{m} .
\end{array}
$$

Each spouse decides on consumption of the private good and the public good in his or her sphere, taking the public good provision by the other spouse as given. The solutions to the above equations are demand functions for the public goods $q_{f}\left(I_{f}, \bar{q}_{m}\right)$ and $q_{m}\left(I_{m}, \bar{q}_{f}\right)$, the intersection of which defines the non-cooperative equilibrium level of public-good provision. Since the two partners strategically interact in the non-cooperation case, their outside options will depend not only on their own income, but also on that of their spouse, i.e. $U_{f}^{0}=U_{f}^{0}\left(I_{f}, I_{m}\right)$ and $U_{m}^{0}=U_{m}^{0}\left(I_{m}, I_{f}\right)$.

Lundberg and Pollak (1993) argue that the validity of the separate spheres bargaining model can be tested using policy reforms that target transfers (like child benefits or allowances) towards mothers. Consider a transfer $t$ that is paid to families with children. Since after divorce children (usually) stay with the mother, in the divorce threat bargaining model the transfer will end up with the woman in the case of non-cooperation, i.e. the outside options will be $U_{f}^{0}\left(I_{f}+t\right)$ and $U_{m}^{0}\left(I_{m}\right)$, regardless of whether during marriage the transfer is targeted toward the husband or the wife. Hence, to which spouse the transfer is targeted during marriage should not affect the allocation of consumption. In the separate spheres model, in contrast, the outside option is non-cooperation during marriage. In this scenario, who the transfer is targeted towards matters for the outside option. When the wive receives the transfer, the outside options are $U_{f}^{0}\left(I_{f}+t, I_{m}\right)$ and $U_{m}^{0}\left(I_{m}, I_{f}+t\right)$, and vice versa if the husband is the recipient. By shifting outside options, the targeting of the transfer will affect the intra-household allocation during the marriage. Lundberg et al. (1997) provide evidence in favor of this prediction by analyzing a reform of child allowances in the United Kingdom in the 1970s that transferred a substantial amount of 
resources to women. They find that as a result, spending on women's and children's clothing relative to men's clothing increased, which supports the separate spheres model.

\subsection{Intertemporal behavior and commitment}

Up to this point we have focused on static models of intrahousehold resource allocation. When it comes to intertemporal household behavior, two questions arise:

1. Is the bargaining power of the spouses constant over time and if not, how does it evolve and what are its determinants?

2. Can households commit to future consumption plans that they agreed on at a certain date?

Basu (2006) criticizes that most of the literature on intrahousehold resource allocation either takes the bargaining power of two partners as given or assumes that it depends solely on exogenous factors. In his view, it is not only the balance of power between two partners that determines their choices, but it is also choices that determine the balance of power. More concretely, he develops a setup where the wife's bargaining power increases in her labor earnings, which depend not just on the exogenous wage but also on endogenous labor supply. He shows that this setup can generate multiple stable equilibrium allocations, so that two otherwise identical societies can end up with different levels of female labor supply. In a society with low female labor supply, when the balance of power between the female and the male partners shifts for some exogenous reason, the economy may shift to the equilibrium with high labor supply, resulting in a dramatic increase in female labor supply for a small change in the environment.

Mazzocco (2007) asks whether households can commit to consumption plans they make at a certain date. A commitment problem can arise when a couple makes a consumption plan at time $t$ for any future period $t+k$ which causes a participation constraint of one spouse to be violated. If there is lack of commitment, the spouses need to take this commitment

problem into account when forming their plans, which puts additional restrictions on the consumption and savings behavior of married couples. Mazzocco (2007) shows that CEX data rejects the assumption of full commitment, suggesting that limited commitment is an important factor limiting couple's ability to achieve an ex-ante efficient allocation.

Summing up, the family economics literature has developed strong evidence that the intrahousehold allocation of resources is not well described by the maximum of a unitary 
household welfare function. Instead, the resolution of conflicting interests between different household members plays an important role. Household bargaining models have proven useful in understanding the determinants of intrahousehold decision making. When applying such models, however, one has to carefully address a few issues, namely the specification of outside options, the determinants of bargaining power, and whether households are able to commit to future actions.

\section{Fertility as an intrahousehold decision}

One of the most profound decisions for a couple is how many children to have. Children are costly in terms of money and time, they need to be taken care of for many years, and they can have a major impact on the spouses' labor supply and career prospects. In this section, we discuss how the theories of intrahousehold decision making described above can be applied to fertility choice. We start with a discussion of the implications of the unitary model of the household for fertility choice, and then consider the implications of models that allow for conflict within the household.

\subsection{The unitary model applied to fertility decisions}

Starting with the seminal contribution of Becker (1960), most of the economic literature on fertility choice has been cast within the unitary model of the household, where decisions are derived from a common utility function for the household. In its simplest form, this model of fertility decisions assumes there to be a household consisting of a female and a male wage earner with wages $w_{f}$ and $w_{m}$ and other income $I_{f}$ and $I_{m}$. The household decides on consumption $c$ and on how many children to have $n$. Children are costly in that they require a goods expenditure of $q$ per child (e.g., food and clothing). In addition, there is a time cost of $z$ per child. The preferences of the household for consumption and the number of children can be represented by a utility function $u(c, n)$, where both goods are normal. Assuming that $w_{f} \leq w_{m}$, it is optimal for the wife to provide child care, so that the household maximizes utility subject to the budget constraint

$$
c+q n=(1-z n) w_{f}+w_{m}+I_{f}+I_{w} .
$$

From this optimization problem we can derive demand functions for consumption and children $c\left(w_{f}, w_{m}, I_{f}+I_{w}\right)$ and $n\left(w_{f}, w_{m}, I_{f}+I_{w}\right)$. It is straightforward to show that we 
have

$$
\frac{\partial n}{\partial w_{m}} \geq 0 \quad, \quad \frac{\partial n}{\partial w_{f}} \gtrless 0 \quad \text { and } \quad \frac{\partial n}{\partial I_{f}}=\frac{\partial n}{\partial I_{m}} \geq 0 .
$$

Hence, a rise in the husband's labor income will increase the number of children, whereas a rise in the wife's wage has ambiguous effects. On the one hand, a rise in the female wage generates a positive income effect, which leads to a higher demand for children. On the other hand, the rise in the wage increases the cost of child care, thereby reducing the the demand for children through a substitution effect. Building on these effects, Jones et al. (2011) discuss how different assumptions on the household optimization problem shape the cross-sectional distribution of fertility in a society.

\subsection{Empirical evidence against unitary models of fertility choice}

An important implication of the unitary model of fertility choice is that effect of an increase non-labor income $I_{i}$ on fertility is positive and identical for male and female income, i.e., transferring a given amount of money to either the wife or the husband should result in the same increase in fertility. Schultz (1990) tests whether this implication holds in the data. Using data from the 1981 Socioeconomic Survey of Thailand, he finds that only transfer income to women has a significant impact on the number of children. In contrast, men's transfer income appears to be put to other uses. A similar analysis is carried out by Klawon and Tiefenthaler (2001). Using Brazilian household data, they find that increases in non-wage income of both husband and wife lower fertility. The negative sign does not necessarily contradict the unitary model, as this could be due to a substitution of child quantity for child quality as income goes up. However, the effect of female non-wage income on fertility is also found to be substantially larger than that of male non-wage income, which speaks against the unitary model.

Hener (2014) uses child preference data from the German Socioeconomic Panel (GSOEP) to analyze to whether couples bargain over fertility. If bargaining is relevant and couples have different preferences for children, then the distribution of bargaining power should matter for the fertility outcome. The GSOEP asks couples in several waves about the importance of having children (measured on a four-point scale). Using this information, couples can be classified depending on whether there child preferences are aligned. Using the relative income of the female partner as a proxy for bargaining power, he finally 
finds that for couples with conflicting preferences, the woman's bargaining power has a significant impact on the fertility outcome.

This evidence suggests that the unitary model provides an incomplete picture of the economic determinants of fertility decisions. As a consequence, a literature has emerged that treats fertility as a more complex decision between a mother and father with potentially conflicting views about fertility.

\subsection{The collective model of fertility choice}

Blundell et al. (2005) use Chiappori's collective model of the household to study fertility. The model is based on the labor supply and consumption choice model of Chiappori (1988, 1992), but extended by a public consumption good (which can be interpreted as children). Unlike in the model outlined in Section 3.1, their model recognizes that mother and father may have different preferences, which can be represented by individual utility functions $U_{i}\left(c_{i}, n\right)$ over private consumption $c_{i}$ and children $n .{ }^{9}$ Given the efficiency assumption of the collective model, the resource allocation of the household can be represented as the solution to the optimization problem

$$
\max _{c_{f}, c_{m}, n} \lambda \cdot U_{f}\left(c_{f}, n\right)+(1-\lambda) \cdot U_{m}\left(c_{m}, n\right)
$$

subject to the budget constraint

$$
c_{f}+c_{m}+q n=(1-z n) w_{f}+w_{m}+I_{f}+I_{w} .
$$

Here the Pareto weight $\lambda$ need not be constant (in which case the model reduces to the unitary model), but can be a function of the individual wages $w_{i}$, non-labor incomes $I_{i}$, as well as some other exogenous determinants $z$, i.e. $\lambda=\lambda\left(w_{f}, w_{m}, I_{f}, I_{m}, z\right)$.

Cherchye et al. (2012) take an extended version of the model of Blundell et al. (2005) to the data using the Longitudinal Internet Studies for the Social sciences (LISS) survey. The survey is conducted in panel form and contains detailed information on time use and household expenditure of Dutch couples. They find that spouses' Pareto weights vary with the wage rates as well as the female share in non-labor income, and the Pareto weights, in turn, affect expenditures on children, as predicted by the model. Interestingly,

9 We abstract from leisure preferences and endogenous labor supply here. 
they also find that empowering women-in the sense of giving them a higher market wage-may lead to less total expenditure on children.

\subsection{Female empowerment and the demand for children}

In Blundell et al. (2005), the different preferences of women and men regarding fertility are taken as primitives. Another approach is to develop microfoundations that provide specific reasons why the incentives for childbearing may differ between women and men. One such paper is Eswaran (2002), who considers a model in which couples decide about the number of children as well as on how much to invest in their children's health. Health investments increase children's probability of surviving to adult age, which is beneficial for the parents because they receive financial support from their children when old. Formally, assume that a couple receives a fixed market income $w$ and decides on how many children to have $n$ and on how much to spend per child $q$. The survival probability of the child is an increasing and concave function of spending, so that the survival probability is also given by $s(q)$. Parents consume during the period when they have children and when old. Consumption is treated as a public good, so that husband and wife always consume the same amount, valued according to the concave utility function $u(c)$. When old, parents rely on transfers I from each of their surviving children. The husband's utility function can then be written as

$$
U_{m}(n, q)=u(w-q \cdot n)+u(s(q) \cdot n \cdot I)
$$

where the second part captures the utility derived from consumption when old. The wife faces a different tradeoff, because a high fertility rate is detrimental to the health of the mother. Eswaran (2002) captures this effect by means of a damage function $D(n)$ with $D^{\prime}(n)<0$ and $D(0)=1$. The utility function of the wife is

$$
U_{f}(n, q)=D(n) \cdot[u(w-q \cdot n)+u(s(q) \cdot n \cdot I)] .
$$

The couple plays a Nash bargaining game with the woman's bargaining power being denoted by $\alpha$. Consequently, the demand for children and health expenditure are the solutions to the optimization problem

$$
\max _{n, h}\left[U_{f}(n, q)-U_{f}^{0}\right]^{\alpha} \cdot\left[U_{m}(n, q)-U_{m}^{0}\right]^{1-\alpha},
$$


where $U_{f}^{0}$ and $U_{f}^{0}$ are exogenous outside options.

In this setup, female empowerment can be achieved either through an increase in the outside option $U_{f}^{0}$ or an increase in the bargaining weight $\alpha$. Eswaran (2002) shows that both kinds of empowerment lead to a lower demand for children and to a simultaneous increase in health expenditure. The mother carries a larger burden of child bearing through the damage done to her health, and hence if her bargaining position improves, this damage will receive more attention in the couple's decision process, leading to a lower demand for children. The decline in fertility, in turn, raises the marginal return of investing in the children's health, in order to ensure sufficient resources in old age. The result is similar to the well-known quantity-quality tradeoff that was already proposed by Becker and Lewis (1973).

Empirically, the prediction that a higher female bargaining power leads to lower fertility is supported by the work of Seebens (2006). Using data from the Demographic and Health Surveys, he finds a negative relationship between the number of children and the wife's bargaining weight in rural Ethiopia. Ashraf et al. (2014) provide additional evidence that increasing the bargaining power of women leads to lower fertility rates in an experimental study in Zambia. In their study, they give women access to contraceptive measures. Some of the women get to learn about this together with their husbands, while others are told about the availability of concealable contraceptive measures alone. For the second group of women, this acts like an implicit increase in bargaining power, since they can decide on their own whether to use contraceptive measures. Ashraf et al. (2014) find that women in the first group, who were told about the availability of contraception measures with their husband present, were 25 percent less likely to actually use them and 27 percent more likely to give birth than women in the second group.

\subsection{Endogenous bargaining power through educational investment}

In the models discussed so far, the determinants of bargaining power are considered to be outside of the control of the couple. Echevarria and Merlo (1999) argue, however, that bargaining power can also depend on endogenous choices. They analyze an overlappinggenerations model where parents are altruistic towards their children. In each cohort, men and women first decide on whether to get married. All married couples give birth to two children, a boy and a girl. Singles are childless. Children are costly in that the woman loses part of her income due to childbearing. In addition, the couple can invest in the 
children's education. Education effort can be targeted towards boys or girls. The model is dynamic in the sense that the children's future bargaining problem as adults is taken into account by the parents. Echevarria and Merlo (1999) find (in line with Becker, 1991) that parents invest more into boys than into girls. The reason is that girls face a lower return to education due to the loss of earnings during child rearing. However, there is also a counteracting force: investing in a girl's education strengthens her outside option in the bargaining process, and therefore increases her share in total consumption.

Iygun and Walsh (2007) pursue a similar idea. In their model couples make decisions in two successive periods. In the first period, husband and wife decide non-cooperatively on the effort they put into their own education. In the second period, the couple bargains over the distribution of consumption and leisure as well as the number of children. Having children is costly in terms of time, where women bear a larger share of this cost. Iygun and Walsh (2007) show that women invest more into their education than what would be Pareto efficient, in order to strengthen their bargaining power in marriage. Because women prefer smaller families due to their high cost share, this also implies that couples will have too few children. More generally, an increase in women's access to education would result in higher female bargaining power and lower fertility.

\subsection{The feedback of fertility on bargaining power}

It is not only pre-marital investments that can determine bargaining power and the distribution of resources in the family; decisions taking during marriage, and in particular fertility decisions, can influence future bargaining power as well. This reverse impact channel of fertility on the resource allocation is studied by Rasul (2008). He proposes a model in which husband and wife derive utility from consumption and having children. There is a fixed cost for each child, and the couple has to decide on fertility before the allocation of consumption is determined. In this setting, Rasul (2008) shows that the ability, or lack thereof, of spouses to commit to future actions plays and important role. If there is full commitment, the couple's decision on fertility will reflect both spouses'

preference for children, and an efficient outcome will be reached. Under a lack of commitment, however, after the arrival of a child there is room for renegotiation between the spouses. Rasul (2008) assumes that the outside option if there is ex-post renegotiation is a non-cooperative equilibrium as in Lundberg and Pollak (1993). In this non-cooperative equilibrium, the husband still derives utility from the presence of children, but the burden of raising the children falls on the wife. Thus, having children implies a loss of bargaining 
power for the wife, and given that the wife is assumed to have the final word on the initial fertility decision, the result is inefficiently low fertility. Rasul (2008) confronts the predictions of his model with household data from the Malaysian Family Life Survey, and finds results that suggest a significant lack of commitment in the marital bargaining process.

Fisher (2012) extends the model of Blundell et al. (2005) to study the commitment problem in a collective model. In her model, the Pareto weights $\lambda(n)$ are a function of the number of children $n$. If households can commit to any future action then they will maximize overall ex-ante welfare:

$$
\max _{c_{f}, c_{m}, n} \lambda(0) \cdot U_{f}\left(c_{f}, n\right)+(1-\lambda(0)) \cdot U_{m}\left(c_{m}, n\right) .
$$

In contrast, if there is lack of commitment, fertility and consumption are determined by a two-stage process. After fertility has already been determined, the distribution of consumption between the partners will reflect the ex-post Pareto weights, i.e. the consumption distribution conditional on the number of children $c_{f}(n)$ and $c_{m}(n)$ is the solution to

$$
\max _{c_{f}(n), c_{m}(n)} \lambda(n) \cdot U_{f}\left(c_{f}, n\right)+(1-\lambda(n)) \cdot U_{m}\left(c_{m}, n\right) .
$$

Taking the ex-post allocation into account, the spouses decide on their number of children in the first stage by solving

$$
\max _{n} \lambda(0) \cdot U_{f}\left(c_{f}(n), n\right)+(1-\lambda(0)) \cdot U_{m}\left(c_{m}(n), n\right) .
$$

Fisher (2012) shows that depending on the relative preferences of the spouses for children and the change in Pareto weights, a lack of commitment can lead to either higher or lower fertility for the couple compared to an ex-ante efficient allocation.

Kemnitz and Thum (2014) pursue similar ideas to study the effects of family policy. In their model, the Pareto weight of the spouses is a function of earnings. In addition to the number of children, the spouses decide on whether the wife should stay at home and care for the children (which reduces her earnings) or whether to buy child care and have both spouses work full-time in the market. If the wife stays at home, a larger number of children causes a decline in her bargaining power and therefore a loss in utility. The couple once again engages in a two step decision process. In the first period they decide about the number of children, and in the second period the allocation of consumption and the 
purchase of child care are chosen. Kemnitz and Thum (2014) argue that the sequentiality of the decision process causes fertility to be too low for couples with low wage females. Couples where the wife has high earnings and works full time face a different decision process for fertility, since these couples buy childcare and the number of children does not affect ex-post bargaining power. The authors study which government interventions can lead to efficient fertility. They find that child allowances, maternal care benefits, and subsidies for external child care would all do the job. However, child allowances turn out to be the most costly measure to achieve this goal.

Komura (2013) proposes a model in which the balance of power in the household is determined not by the individual fertility decision, but through social interactions, i.e., the fertility choices of the total population. Bargaining power is endogenous for the whole economy, but taken as given by individual couples, who act as "price takers" in this sense. The decision process is therefore as in the standard collective model, see (22). However, the bargaining weights are a function of aggregate fertility in equilibrium. Komura (2013) shows that in this setup there exist multiple stable equilibria. One reflects a patriarchal society with a high fertility rate, and the other one is characterized by empowered women and low fertility.

\subsection{Bargaining, fertility decisions, and the marriage market}

Another strand of the literature explores the interactions between fertility, the marriage market, and the distribution of income. In the overlapping-generations model of Greenwood et al. (2003) men and women live for four periods. In the first two they are children that receive educational investments from their parents. In the third period they reach maturity, enter the labor force, and learn about their individual wage rate. Wages are stochastic over the life cycle and follow a Markov process. Having reached maturity, individuals can start searching for a spouse in the marriage market. If a suitable potential spouse arrives, the couple can get married. If no suitable partner is available, the individual can search again in the last period. In addition to the marital and labor market decisions, couples as well as single women have to decide about whether to have children and how many to have. Fertility is restricted to the first period of adult life. If children are born, parents can invest in their human capital. Decisions within a marriage are made through Nash-bargaining with the outside option being divorce. The matching probabilities between partners of different gender are computed such that the marriage market is 
in equilibrium. Greenwood et al. (2003) analyze whether child policy measures can increase society's welfare. They find that holding the marriage market allocation constant, child tax credits increase the amount of income per child. However, they also reduce the attractiveness of marriage for females. In total, it is questionable whether such tax credits can actually increase social welfare.

Caucutt et al. (2002) extend the model of Greenwood et al. (2003) by allowing for a second child bearing period and experience effects in labor productivity (measured as the amount of labor supplied to the market in the previous period). They find that their model can explain why higher wage women usually have children later in life. The reason is that these women are pickier in the marriage market, in the sense that it is not optimal for them to have a lower-wage husband. Given these incentives, they need more time to find a suitable husband and therefore bear children later in life.

Finally, Guner and Knowles (2009) use the model of Greenwood et al. (2003) to compare the effects of welfare policies in the United States and Canada. While in the United States "Aid to Families with Dependent Children" transfers are targeted specifically towards single women, implicitly rewarding them for out-of-marriage fertility, in Canada such aid transfers are simply means tested. The authors argue that the differences in these aid policies explain almost all of the difference in the number of children aged 0-8 between the United States and Canada. They furthermore find that the Canadian policy is more effective in helping poor children and increasing their human capital levels, thereby reducing long-run inequality. Yet, the U.S. policy is less costly and leads to higher average income. From an ex-ante welfare perspective, however, households would prefer the Canadian over the U.S. policy.

\section{Ongoing Research and Outlook}

The literature surveyed above has established clear evidence that intra-household bargaining is a key determinant of fertility. In addition, the literature has identified a number of channels for feedback between fertility decisions and other important household choices through the endogenous evolution of bargaining power. In our ongoing work, Doepke and Kindermann (2014), we build on the existing literature while also making additional contributions in terms of theory, empirics, and policy implications.

In terms of theory, the existing models assume either that just one spouse (i.e., the wife) ultimately controls fertility, or that fertility is decided through a cooperative bargaining 
process that maximizes a weighted sum of the spouses' utilities. These settings do not represent the distinct nature of the fertility decision, which is that cooperation from both spouses is required (whereas most other goods can, in principle, be acquired by each spouse individually), and that at any time there is a well defined status quo, namely not to have a (or another) child. Hence, our point of departure is a dynamic bargaining model that exhibits limited commitment (building on the insights from the existing literature) while also requiring that a child can be born only with agreement from both spouses. This need for agreement leads to distinct implications that we believe to be important for understanding the determinants of fertility rates across countries and for the potential effects of fertility-oriented policies.

In terms of empirics, we use data from a new survey, the Generation and Gender Program, which is carried out in panel form in several (mostly European) countries. In most of the countries, the survey explicitly asks about the preferences of spouses for the arrival of another child. Making use of the fact that we can observe the fertility outcome of a couple in the subsequent wave, we can analyze how couples with aligned and differing preference decide on the arrival of children. The data present a detailed picture of household bargaining over fertility that is not available in previous studies. A few key observations in the data are that there are many couples that disagree over having a baby; that whether husbands or wives are more likely to be opposed to having a baby varies hugely across countries; and that when there is disagreement in the household, the likelihood of a birth is indeed much reduced. We use the data to structurally estimate a dynamic model of fertility decision making. Using the estimated model, we argue that the distribution of costs of children between husband and wife explains a significant chunk of the fertility differences across European countries. More specifically, we find that in countries where the men do rather little of the work in child rearing, fertility rates are substantially lower than in countries with a higher participation of men in child care. The intuitive reason for this is that women object to having another baby if they have to do all the work.

In terms of policy implications, our results suggest that government policy can affect fertility not only through its effect on the overall cost of having children, but also through affecting the distribution of costs and benefits of child bearing between mother and father. This is especially relevant in countries with a lopsided distribution of agreement and disagreement over childbearing, which characterizes the European countries with the lowest fertility rates (where it is primarily the mothers that object to having more children). As an example, this insight could be useful for understanding the contrasting fertility policies and outcomes in countries such as the United States and Germany. In the United States, 
hardly any child benefits or maternal allowances are provided. In Germany, in contrast, the government pays a cash allowance for each child, there is a generous maternal leave policy, and public child care starting from age 4 is highly subsidized. Yet, fertility rates are much lower in Germany compared to the United States. Through the lens of our model, this observations might be due to the impact of policy on the distribution of the burden of child care within the family. We think that the German policy, with its generous maternal leave but relative lack of publicly provided childcare for the youngest children, is designed in such a way that it pushes women out of the labor force. In the United States, in contrast, the lack of maternal leave policies induces many women to continue working and rely on market-based child care. A side effect of this is that in the United States we would expect a more equal sharing of the costs of children between the spouses (because both earners can contribute cash to buying market-based child care).

If this interpretation is correct, it also implies that policies that directly address the lopsided distribution of the burden of childcare among the spouses in countries like Germany are much more likely to be successful than policies that simply increase overall subsidies towards childbearing. Indeed, we believe that a number of actual policy measures currently being implemented in various countries (such providing parental leave specifically for fathers) are based on this intuition. By modeling the bargaining process over fertility explicitly and incorporating the need for agreement, the economic theory of fertility will be able to speak to these questions and guide future policy making in the area.

\section{References}

Ashraf, N., E. Field and J. Lee (2014): Household Bargaining and Excess Fertility: An Experimental Study in Zambia, American Economic Review 104 (7), 2210-2237.

Basu, K. (2006): Gender and Say: A Model of Household Behavior with Endogenously Determined Balance of Power, Economic Journal 116 (511), 558-580.

Becker, G. (1991): A Treatise on the Family, Harvard University Press, Cambridge.

Becker, G. S. (1960): An Economic Analysis of Fertility, In: G. B. Roberts (Ed.), Demographic and Economic Change in Developed Countries, Princeton University Press, Princeton, 209-240.

Becker, G. S. (1973): A Theory of Marriage: Part I, Journal of Political Economy 81 (4), 813-846. 
Becker, G. S. (1974): A Theory of Marriage: Part II, Journal of Political Economy 82 (2), S11-S26.

Becker, G. S. and H. G. Lewis (1973): On the Interaction between Quantity and Quality of Children, Journal of Political Economy 81 (2, Part 2), S279-S288.

Blundell, R., P.-A. Chiappori and C. Meghir (2005): Collective Labor Supply with Children, Journal of Political Economy 113 (6), 1277-1306.

Browning, M., F. Bourguignon, P.-A. Chiappori and V. Lechene (1994): Income and Outcomes: A Structural Model of Intrahousehold Allocation, Journal of Political Economy 102 (6), 1067-1096.

Browning, M. and P.-A. Chiappori (1998): Efficient Intra-Household Allocations: A General Characterization and Empirical Tests, Econometrica 66 (6), 1241-1278.

Caucutt, E. M., N. Guner and J. Knowles (2002): Why do Women Wait? Matching, Wage Inequality, and the Incentives for Fertility Delay, Review of Economic Dynamics 5 (4), $815-855$.

Cherchye, L., B. De Rock and F. Vermeulen (2012): Married with Children: A Colective Labor Supply Model with Detailed Time Use and Intrahousehold Expenditure Information, American Economic Review 102 (7), 3377-3405.

Chiappori, P.-A. (1988): Rational Household Labor Supply, Econometrica 56 (1), 63-90.

Chiappori, P.-A. (1992): Collective Labor Supply and Welfare, Journal of Political Economy 100 (3), 437-467.

Doepke, M. and F. Kindermann (2014): Bargaining over Babies: Theory and Application to Fertility in Europe, Working Paper, Northwestern University.

Doepke, M. and M. Tertilt (2014): Does Female Empowerment Promote Economic Development?, NBER Working Paper 19888.

Echevarria, C. and A. Merlo (1999): Gender Differences in Education in a Dynamic Household Bargaining Model, International Economic Review 40 (2), 265-286.

Eswaran, M. (2002): The Empowerment of Women, Fertility, and Child Mortality: Towards a Theoretical Analysis, Journal of Population Economics 15 (2), 433-454.

Fisher, H. (2012): Fertility in a Collective Housheold Model, Unpublished Manuscript , Sydney.

Greenwood, J., N. Guner and J. Knowles (2003): More on Mariage, Fertility, and the Distribution of Income, International Economic Review 44 (3), 827-862. 
Guner, N. and J. Knowles (2009): Why is the Rate of Single-Parenthood Lower in Canada than in the U.S.? A Dynamic Equilibrium Analysis of Welfare Policies, Canadian Journal of Economics 42 (1), 56-89.

Hener, T. (2014): Do Couples Bargain over Fertility?, Annals of Economics and Statistics Special Volume: Economics of Gender, forthcoming.

Iygun, M. and R. P. Walsh (2007): Endogenous Gender Power, Household Labor Supply and the Demographic Transition, Journal of Development Economics 82 (1), 138-155.

Jones, L., A. Schoonbroodt and M. Tertilt (2011): Fertility Theories: Can They Explain the Negative Fertility-Income Relationship, In: J. B. Shoven (Ed.), Demography and the Economy, University of Chicago Press, Chicago, 43-100.

Kemnitz, A. and M. Thum (2014): Gender Power, Fertility, and Family Policy, Scandinavian Journal of Economics, forthcoming.

Klawon, E. and J. Tiefenthaler (2001): Bargaining over Family Size: The Determinants of Fertility in Brazil, Population Research and Policy Review 20 (5), 423-440.

Komura, M. (2013): Fertility and Endogenous Gender Bargaining Power, Journal of Population Economics 23 (3), 943-961.

Lundberg, S. and R. A. Pollak (1993): Separate Spheres Bargaining and the Marriage Market, Journal of Political Economy 101 (6), 988-1010.

Lundberg, S. and R. A. Pollak (1994): Noncooperative Bargaining Models of Marriage, American Economic Review 84 (2), 132-137.

Lundberg, S., R. A. Pollak and T. Wales (1997): Do Husbands and Wives Pool Their Resource? Evidence from the United Kingdom Child Benefit, Journal of Human Resources 32 (3), 463-480.

Manser, M. and M. Brown (1980): Marriage and Household Decision-Making: A Bargaining Analysis, International Economic Review 21 (1), 31-44.

Mazzocco, M. (2007): Household Intertemporal Behavior: A Collective Characterization and a Test of Commitment, Review of Economic Studies 74 (3), 857-895.

McElroy, M. B. and M. J. Horney (1981): Nash-Bargained Household Decisions: Toward a Generalization of the Theory of Demand, International Economics Review 22 (2), 333-349.

Rasul, I. (2008): Household Bargaining over Fertility: Theory and Evidence from Malaysia, Journal of Development Economics 86 (2), 215-241. 
Schultz, T. P. (1990): Testing the Neoclassical Model of Family Labor Supply and Fertility, Journal of Human Resources 25 (4), 599-634.

Seebens, H. (2006): Bargaining over Fertility in Rural Ethiopia, Unpublished Manuscript , Göttingen.

Westoff, C. F. (2010): Desired Number of Children: 2000-2008, DHS Comparative Reports No. 25. 